\title{
Atypical Trigeminal Neuralgia
}

\section{Azza Almatt*}

Department of Endodontics, Saudi Arabia

*Corresponding Author: Azza Almatt, Department of Endodontics, Saudi Arabia.

Received: August 19, 2019; Published: September 06, 2019

DOI:_10.31080/ASDS.2019.03.0635

\section{Case Report Draft}

AMy patient A. A has visited my dental office for the retreatment of upper first molar right side. The patient was suffering from headache since 2 years ago, she made MRI twice last year, frequently visited the neurology Department in another hospital.

The neurologists were unsure of the definite diagnosis of the state, and they requested further investigation through MRI with intervals every 6 months.

The second visit for the patient to our dental department, she started to explain more and more specifically describe her headache, she said, my headache is of one side the right side, too irritating like attacks from the right angle of the forehead, my right eye, she referred to the right side of the temporal bone and described her pain as it is an open wound, like electrical current hits an open wound intervals, twice a week ...or more sometimes.

After the re- treatment of the upper first molar right side, the symptoms stayed the same as I realized that this tooth had nothing to do with that aggressive pain.

I started to investigate deeper in the issue, I counted the number of Amalgam fillings she had, they were five ones made more than five years ago, some of them had the shiny appearance that indicate the high levels of mercury.

I requested lead blood level, and mercury blood level .........

We started follow up visits to replace these fillings with composite.

I reexamined the upper right jaw again by palpation, extremely painful response was existed when I palpated the upper second implant placed for the premolar.
Periapical $\mathrm{x}$-ray taken again, for the area, I noticed that the maxillary sinus was involved, the implant violated this biological area. I asked the patient not to repeat MRI, anymore, as this procedure would stimulate the symptoms, severely especially with the existence of the upper implant.

I reduced the occlusion on that implant by using articulatory paper.

I asked the patient not to chew on the right side at all. My initial diagnosis, that the patient has Atypical Trigeminal Neuralgia.

I sought the patient relatives notes about her, they claimed that she was easily irritated lately, didn't like loud voices, or intensive light.

That emphasized my diagnosis, I then, urged the patient never to do MRI.

I totally reduced the occlusal surface of the upper implant, as I disfunction it totally.

Symptoms improved a week after a week.

I urged the patient that the removal of the upper implant is mandatory and immediately.

I prescribed tigritol $200 \mathrm{mg}$ TID, till symptoms subside.

That journey with my dear patient taught me a lot, most of what I learned that the nerve endings for the cranial nerves are of the same level of importance as their trunks.

\section{Volume 3 Issue 10 October 2019}

(C) All rights are reserved by Azza Almatt. 